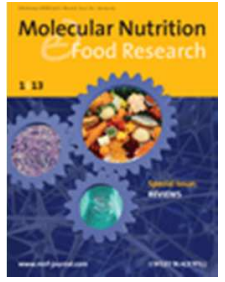

\title{
Hydroxytyrosol and its complex forms (secoiridoids) modulate aorta and heart proteome in healthy rats: potential cardio-protective effects
}

\begin{tabular}{|r|l|}
\hline Journal: & Molecular Nutrition and Food Research \\
\hline Manuscript ID & Draft \\
\hline Wiley - Manuscript type: & Research Article \\
\hline Date Submitted by the Author: & n/a \\
\hline Complete List of Authors: & $\begin{array}{l}\text { Catalán, Úrsula; Functional Nutrition, Oxidation and Cardiovascular } \\
\text { Diseases Group (NFOC-Salut), Unit of Lipids and Atherosclerosis Research } \\
\text { (URLA), Centro de Investigación Biomédica en Red de Diabetes y } \\
\text { Enfermedades Metabólicas Asociadas (CIBERDEM), Hospital Universitari } \\
\text { Sant Joan, IISPV, Technological Center of Nutrition and Health (CTNS), } \\
\text { Faculty of Medicine and Health Sciences, Universitat Rovira i Virgili, Sant } \\
\text { Llorenc, 21, 43201, Reus, Spain } \\
\text { Rubió, Laura; Functional Nutrition, Oxidation and Cardiovascular Diseases } \\
\text { Group (NFOC-Salut), Unit of Lipids and Atherosclerosis Research (URLA), } \\
\text { Centro de Investigación Biomédica en Red de Diabetes y Enfermedades } \\
\text { Metabólicas Asociadas (CIBERDEM), Hospital Universitari Sant Joan, IISPV, } \\
\text { Technological Center of Nutrition and Health (CTNS), Faculty of Medicine } \\
\text { and Health Sciences, Universitat Rovira i Virgili, Sant Llorenç, 21, 43201, } \\
\text { Reus, Spain } \\
\text { López de las Hazas, Maria-Carmen; Food Technology Department, } \\
\text { Universitat de Lleida-AGROTECNIO Center, Lleida, Alcalde Rovira Roure } \\
\text { 191, 25198 Lleida, Spain } \\
\text { Herrero, Pol; Centre for Omic Sciences, Universitat Rovira i Virgili (COS- } \\
\text { URV), Reus, Spain } \\
\text { Nadal, Pedro; Centre for Omic Sciences, Universitat Rovira i Virgili (COS- } \\
\text { URV), Reus, Spain } \\
\text { Canela, Núria; Centre for Omic Sciences, Universitat Rovira i Virgili (COS- } \\
\text { URV), Reus, Spain } \\
\text { Pedret, Anna; Functional Nutrition, Oxidation and Cardiovascular Diseases } \\
\text { Group (NFOC-Salut), Unit of Lipids and Atherosclerosis Research (URLA), } \\
\text { Centro de Investigación Biomédica en Red de Diabetes y Enfermedades } \\
\text { Metabólicas Asociadas (CIBERDEM), Hospital Universitari Sant Joan, IISPV, } \\
\text { Technological Center of Nutrition and Health (CTNS), Faculty of Medicine } \\
\text { and Health Sciences, Universitat Rovira i Virgili, Sant Llorenç, 21, 43201, } \\
\text { Reus, Spain } \\
\text { Motilva, Maria-José; Food Technology Department, Universitat de Lleida- } \\
\text { AGROTECNIO Center, Lleida, Alcalde Rovira Roure 191, 25198 Lleida, } \\
\text { Spain }\end{array}$ \\
\hline
\end{tabular}




\section{SCHOLARONE ${ }^{m}$}

Manuscripts

SOLA, Rosa; Unitat de Recerca en Lípids i Arteriosclerosis (CIBERDEM), Hospital Universitari St. Joan de Reus, IISPV, Universitat Rovira i Virgili,

Keywords: hydroxytyrosol, secoiridoids, healthy rats, proteome, cardiovascular disease 


\section{Hydroxytyrosol and its complex forms (secoiridoids) modulate aorta and heart proteome in healthy rats: potential cardio-protective effects}

Úrsula Catalán $^{1 *}$, Laura Rubió ${ }^{1,2 *}$, Maria-Carmen López de las Hazas ${ }^{2}$, Pol Herrero ${ }^{3}$, Pedro Nadal ${ }^{3}$, Núria Canela ${ }^{3}$, Anna Pedret ${ }^{1}$, Maria-José Motilva ${ }^{2 \dagger}$ and Rosa Solà ${ }^{1 \dagger}$

${ }^{1}$ Functional Nutrition, Oxidation and Cardiovascular Diseases Group (NFOC-Salut), Unit of Lipids and Atherosclerosis Research (URLA), Centro de Investigación Biomédica en Red de Diabetes y Enfermedades Metabólicas Asociadas (CIBERDEM), Hospital Universitari Sant Joan, IISPV, Technological Center of Nutrition and Health (CTNS), Faculty of Medicine and Health Sciences, Universitat Rovira i Virgili, Sant Llorenç, 21, 43201, Reus, Spain

${ }^{2}$ Food Technology Department, Universitat de Lleida-AGROTECNIO Center, Lleida, Alcalde Rovira Roure 191, 25198 Lleida, Spain

${ }^{3}$ Centre for Omic Sciences, Universitat Rovira i Virgili (COS-URV), Reus, Spain

*These authors contributed equally to this work.

$†$ Corresponding authors:

Rosa Solà, $\mathrm{MD}, \mathrm{PhD}$

Unitat de Recerca de Lípids i Arteriosclerosi, CIBERDEM, Servei de Medicina Interna Hospital Universitari de Sant Joan, Institut Investigació Sanitària Pere Virgili

Facultat de Medicina, Universitat Rovira i Virgili, C/ Sant Llorenç, 2143201 Reus, SpainTel: (+34) 977759369 / (+34) 609906991 (mobile) Fax: (+34) 977759322

E-mail: $\underline{\text { rosa.sola@,urv.cat }}$ 
and

$\mathrm{M}^{\mathrm{a}}$ José Motilva, $\mathrm{PhD}$

Department of Food Technology, XaRTA-UTPV, Escola Tècnica Superior d'Enginyeria

Agrària, Universitat de Lleida

Avda/Alcalde Rovira Roure 191, 25198 Lleida, Spain.

Tel: +34 973702817 / Fax: +34 973702596

E-mail: motilva@tecal.udl.cat

\section{Abbreviations}

VOO, virgin olive oil

HT, hydroxytyrosol

SEC, secoiridoids

CVD, cardiovascular diseases

TMT, tandem mass tag

3,4-DHPEA-EDA, 3,4-dihydroxyphenolethanol-elenolic acid di-aldehyde

IPA, Ingenuity Pathway Analysis

PCA, principal component analysis

FC, fold change

VSMC, vascular smooth muscle cells 


\begin{abstract}
SCOPE: Hydroxytyrosol (HT) is the major phenolic compound in virgin olive oil (VOO) in both free and complex forms (secoiridoids; SEC). Proteomic of tissues related to cardiovascular system such as aorta or heart represents a novel and promising tool to uncover the mechanisms of action of phenolic compounds in healthy animals.
\end{abstract}

METHODS AND RESULTS: Twelve female Wistar rats were separated into three groups and fed with standard diet and diets supplemented in phenolic compounds (HT and SEC) adjusted to $5 \mathrm{mg} / \mathrm{kg} /$ day during 21 days. Proteomic analyses of aorta and heart tissues were performed by nano-liquid chromatography and mass spectrometry. Ingenuity Pathway Analysis was used to generate interaction networks. HT or SEC modulated aorta and heart proteome compared to the control group. The top-scored networks were related to Cardiovascular System Development. The aortic proteins, Rac1, T-kininogen 2, Gja1 and Hspla1 that promote proliferation and migration of endothelial cells and occlusion of blood vessels were down-regulated after treatments. In heart, Camk2d and Fkbp1a, related to heart failure, were also positively regulated.

CONCLUSION: Results suggest that free HT reach target cardiovascular tissues inducing changes at proteomic level, which may partially account for the underlying mechanisms involved in the cardiovascular protection of VOO phenols.

\title{
Word count: 200
}

Keywords: hydroxytyrosol, secoiridoids, healthy rats, proteome, cardiovascular disease 


\section{Introduction}

Hydroxytyrosol (HT) is the major phenolic compound in virgin olive oil (VOO) in either free and complex forms, which are commonly named secoiridoids (SEC) or oleuropein aglycone derivates. HT has shown a wide range of biological functions, such as antioxidant, anticancer and neuroprotective activities, as well as having beneficial effects on the cardiovascular system [1,2]. With a more significant impact, VOO phenolic compounds have been shown to beneficially alter lipid composition, platelet and cellular function as well as reduce the inflammation [3]. These effects have been related with the low rate of cardiovascular disease (CVD) mortality and certain types of cancer in populations residing in the Mediterranean countries [3].

The impact of the diet and dietary components on CVD has been widely recognized in recent years [4,5]. Therefore, prevention through the introduction of lifestyle and proper nutrition habits is now considered a primary strategy for what we call healthy aging. Omics-based studies, including genomics, transcriptomics, proteomics, and metabolomics, have been recognized as powerful analytical tools in cardiovascular research [6]. Specifically, the proteomic approach offers an unbiased way to study changes in protein levels induced by different experimental conditions and a major challenge of proteome research is detecting clinically useful biomarkers of disease, treatment response and aging [7]. Moreover, proteomic approach instead of the analysis of gene expression, focuses on the products that perform the biological function [8].

Despite that proteomics represents a novel and promising tool to uncover the mechanisms of action as a response to diet or nutrients, the actual use of this technique in dietary interventions is still rather limited [9]. Regarding proteomics focused on 
cardiovascular tissues, very few studies have been performed up to now investigating the possible protective effect on diseased animals of food bioactive compounds on the protein expression of aortic tissue testing vitamin $\mathrm{E}$ and omega-3 fatty acids $[10,11]$ and heart tissue testing resveratrol $[12,13]$. Other studies analyzing proteome on diseased cardiovascular tissues, such as calcific aortic valve or infarcted myocardium have reflected important changes in protein induced by disease [14]. However, to the best of our knowledge, no study has reported so far the modulation of aorta and heart proteome by bioactive compounds, specifically phenolic compounds, in healthy animals to address future cardiovascular protection. Small animal models have provided insight into the fundamental mechanisms driving early atherosclerosis, but it is increasingly clear that new strategies and research tools are needed to translate these discoveries into improved prevention and treatment of symptomatic atherosclerosis in humans.

The hypothesis of the present work is that VOO phenolic compounds could promote protective effects in cardiovascular system in healthy animals. In an effort to understand the underlying molecular mechanisms of VOO phenols and to identify their potential target protein molecules in cardiovascular tissues, in the present study we performed a proteomic comparative analysis of the aorta and heart tissues of healthy female rats in response to supplemented diet with the equivalent of $5 \mathrm{mg}$ phenol/kg rat weight during 21 days of HT as a pure molecule or its complex occurring forms in VOO through an extract rich in SEC, respectively.

\section{Materials and Methods}

\subsection{Chemicals and reagents}

HT was provided by Seprox Biotech (Madrid, Spain), homovanillic acid by Fluka Co. (Steinheim, Switzerland) and catechol from Sigma-Aldrich (St. Louis, MO, 
USA). HT-3'-O-sulfate was purchased from Toronto Research Chemicals Inc. (Toronto, Ontario, Canada). Methanol and acetonitrile (HPLC-grade) were purchased from Scharlab (Barcelona, Spain). Milli-Q water was obtained from a Milli-Q water purification system (Millipore Corp., Medford, MA, USA). Tandem mass tag (TMT) 10-plex isobaric reagents were from Thermo Fisher Scientific (San José, CA, USA). Organic solvents were liquid chromatography-mass spectrometry grade from Panreac (Barcelona, Spain). Unless otherwise noted, all other chemicals were from SigmaAldrich (St. Louis, MO, USA).

\subsection{Secoiridoid extract}

Ethanolic phenolic extract rich in SEC was obtained from Arbequina olive cake by pressurized liquid extraction (ASE 100 Dionex, Sunnyvale, California, USA) based on the method of Suárez et al [15],Extraction conditions were: ethanol/water (80:20, $\mathrm{v} / \mathrm{v})$ at $80^{\circ} \mathrm{C}, 60 \%$ setting volume and two static cycles of $5 \mathrm{~min}$ in each extraction, then, sample was purged with nitrogen ( $\geq 99.99 \%$ purity, Alphagaz, Madrid, Spain). After that, ethanol was rotary evaporated until its elimination (Buchi, New Castle, DE, USA). Aqueous extract was freeze-dried and stored at $-80^{\circ} \mathrm{C}$ in $\mathrm{N}_{2}$ atmosphere until use. The extract was mainly composed by dialdehydic form of decarboxymethyl EA linked to HT or 3,4-DHPEA-EDA (85\%). It also contained minor proportions of free HT and other secoiridoids providing HT such as the isomer of oleuropein aglycone or 3,4DHPEA-EA (Supporting information: Table 1). In order to calculate the administered dose of $5 \mathrm{mg} / \mathrm{kg}$ weight of SEC, only 3,4-DHPEA-EDA was considered as it is the main secoiridoid derivative providing HT.

\subsection{Animals and experimental procedure}

Twelve female Wistar rats weighted among 300-350 g were obtained from Charles River Laboratories (Barcelona, Spain). They were separated into three groups 
with different diets (4 rats in each group): control group (A), HT group (B) and SEC group (C). Animals were housed two per cage in a temperature $\left(21 \pm 1^{\circ} \mathrm{C}\right)$ and humidity $(55 \pm 10 \%)$ controlled room with a 12 -h light/dark cycle. Food and water were available ad libitum in cage and metabolic cages. The animal procedures were conducted in accordance with the guidelines of the European Communities Directive 86/609/EEC regulating animal research and approved by the local ethical committee (CEEAUniversitat de Lleida, reference 7675).

Supplemented diet preparation was based on follow up the food intake and animal weight during 3 days a week. . Briefly commercial fed pellets (Harlan laboratories, Barcelona, Spain) were crushed andmixed with Milli-Q water containing the equivalent of $5 \mathrm{mg}$ of $\mathrm{HT}$ or SEC/kg rat weight in average of daily consumption of each rat and were then freeze-dried.

After 21 days of treatment rats were sacrificed by intracardiac puncture after isoflurane anaesthesia (IsoFlo, Veterinarian Esteve, Bologna, Italy). After blood collection, rats were perfused by isotonic solution of $\mathrm{NaCl} 0.9 \%$ to remove the remaining blood irrigating tissues and heart and aorta were excised from the rats. All samples were stored at $-80^{\circ} \mathrm{C}$ until analysis.

\subsection{Heart tissue sample pre-treatment and phenolic chromatographic analysis}

In order to study the disposition of phenolic compounds on heart tissue after HT or SEC treatments, the free HT and its biological metabolites were determined. Aorta was not analyzed as it was entirely used for proteomic analysis. Prior to the chromatographic analysis, heart was freeze-dried and homogeneus samples were sequentially pre-treated with a combination of liquid-solid extraction combined with micro solid phase extraction as previously described [16]. Phenolic compounds were then analyzed by Acquity Ultra-Performance ${ }^{\mathrm{TM}}$ liquid chromatography coupled to 
tandem MS as the detector system from Waters (Milford, MA, USA), as reported in our previous study [16].

\subsection{Proteomic sample preparation and quantitative analysis of the aorta and heart tissues}

A quantitative proteomic study in aorta and heart rat tissues was performed using TMT isobaric tag labelling, off-gel fractionation and mass spectrometry based on nanoLC-Orbitrap technology was performed (Figure 1). The different analytical steps are explained in detail in supporting information: Materials and Methods.

\subsection{Clustering and pathway analysis}

Various bioinformatics tools were employed for the biological interpretation of the results. Proteins were referred to by their gene encode symbol. Each protein identifier (Swiss-Prot ID) was mapped to its corresponding protein object in the Wiki Pathways, KEGG, Reactome and BioCyte data bases.

Ingenuity Pathway analysis (IPA; Ingenuity System Inc., Redwook, CA, USA, www.ingenuity.com) was used to analyze canonical pathways and protein networks involving the differentially expressed proteins for biological interpretation. Significance levels were assessed with Fisher's exact tests $(p<0.01)$. The differentially expressed proteins were overlaid with IPA-curated canonical pathways to explore possible metabolic and cell signaling pathways that were over- or under-represented by the experimentally determined genes. Specifically, we conducted two analysis: a) the common proteins up- or down-regulated in the same direction after both treatments (HT and SEC) in aorta or heart tissue compared to control group, to study the potential common HT and SEC mechanisms of action, and b) the whole dataset of proteins differentially expressed after HT or SEC treatments in aorta or heart tissue compared to 
control group in order to acquire a global vision and focused on cardiovascular system (Figure 2).

In addition, possible connections between mapped genes were evaluated and graphical networks were algorithmically generated. Nodes representing genes and gene products were linked by biological relationships. Networks were ranked by a score that defines the probability of a collection of nodes being equal to or greater than the number in a network achieved by chance alone.

\subsection{Statistical analysis}

The statistical analysis to find the significant protein changes between conditions included in the present studies was done by Mass Profiler Professional software v. 13.0 from Agilent Technologies (Santa Clara, CA, USA).

The statistical analysis was the same for aortic and heart tissue. The study comprises three different groups named as control, HT and SEC. A 1-Way ANOVA statistical test was applied with a $p$-value correction of Benjamin-Hochberg false discovery rate for multiple comparisons using the quantified proteins that appears in more than $66 \%$ of samples. Moreover multivariate statistical technique based on principal components analysis (PCA) was applied. There are 3 replicates for control condition (one is used for normalization and is not considered for statistical analysis) and 4 replicates for each treatment condition.

\section{Results}

\subsection{Disposition of HT and its metabolites in heart tissue}

As shown in Table 1, after diet supplementation with $5 \mathrm{mg}$ of HT or SEC/kg weight/day during 21 days, free HT was detected in heart tissue mainly in its free form and in a minor proportion as phase II metabolite HT-3-O-sulfate, which only appeared 
after HT treatment. When comparing both treatments, the free form of HT presented significant higher concentrations after SEC diet supplementation compared to HT.

The free HT detected in the heart tissue of the control group could be related to the endogenous origin of this compound from dopamine metabolism previously described [17].

\subsection{Tissue proteome modulation by HT and SEC}

\subsubsection{Aorta}

After performing the proteome analysis of aorta tissue samples, we reached to identify and quantify 1247 proteins. The comparative analysis revealed that from the identified proteins, 115 significantly differed after HT and SEC treatments compared to control group $(p<0.05)$. All these up- or downregulated proteins with their corresponding fold change (FC) values compared to the control group are listed in Table 2 and they have been also classified in a Venn diagram in Figure 2A. The corresponding information for all identified proteins in aorta is available in supporting

\section{information: Table 2.}

The comparative analysis between HT treatment and control group in aorta tissue revealed an up-regulation of 26 proteins ranging from 1.0 to $1.3 \mathrm{FC}$ and a downregulation of 89 proteins from -1.0 to -1.7 of FC. When comparing SEC treatment with control group, we observed an up-regulation of 34 proteins ranging from 1.2 to 16.3 of FC and a down-regulation of 81 proteins from -1.2 to -18.8 of FC. As shown in the Venn diagram (Figure 2A) most of these proteins were significantly modulated in the same direction after the two treatments (HT or SEC) compared to control group, and in most of the proteins FC values were strengthened after SEC diet supplementation compared to HT (Table 2). The PCA of aortic tissue samples after the statistical test showed that only a slightly differentiation between control group and HT group is 
observed but both are significantly different compared to SEC (Supporting information: Figure 1A), which is in accordance with the higher FC values of SEC.

\subsubsection{Heart}

In heart tissue we identified and quantified 1124 proteins and 34 proteins that significantly differed after HT and SEC treatments compared to control group $(p<0.05)$. All the up- or downregulated proteins with their corresponding $\mathrm{FC}$ values compared to the control group are listed in Table $\mathbf{3}$ and have been classified in a Venn diagram shown in Figure 2B. The corresponding information for all the identified proteins in heart is available in supporting information: Table 3.

Comparative between HT treatment and control group revealed an up-regulation of 12 proteins ranging from 1.0 to 1.4 of $\mathrm{FC}$ and a down-regulation of 22 proteins ranging from -1.0 to -1.4 of FC. Comparing SEC treatment to control group, we observed an up-regulation of 22 proteins ranging from 1.0 to 3.4 of FC and a downregulation of 12 proteins ranging from -1.1 to -1.5 of FC. Comparing SEC treatment to HT treatment revealed that 23 proteins were up-regulated (from 1.0 to 3.3 of FC) and 11 were down-regulated (from -1.0 to -2.0 of FC). As in aorta, some of the proteins were differentially expressed in the same direction after the two treatments (HT or SEC) compared to control group (Figure 2B), but in heart, most of the proteins were modulated in opposite directions depending on the treatment. The PCA analysis showed a clear differentiation between the three groups (control, SEC and HT) in heart tissue (Supporting information: Figure 1B).

Among all the differentially expressed proteins, only two proteins, Actn4 and Rp18, were found to be significantly modulated in both aorta and heart tissues.

\subsection{Pathway analysis of common proteins modulated by HT and SEC}


Following the pathway analysis strategy "a" described in section 2.6, we analyzed in IPA the common proteins that were differentially up- or downregulated in the same direction in response to both the HT and SEC consumption in order to investigate common mechanisms after both treatments. Results regarding the top-scored canonical pathways, molecular and cellular functions, diseases and disorders and potential upstream regulators are presented in detail in Supporting information: Results.

\subsection{Global proteome changes after HT or SEC and its relation with Cardiovascular} System

Following the analysis strategy "b" the whole dataset of significantly expressed proteins after HT and SEC treatments in aorta (115 proteins) or heart (34 proteins) tissue compared to control group was analyzed in IPA with special focus on Cardiovascular System functions.

\subsubsection{Aorta tissue}

When the complete dataset of proteins differentially expressed in aorta was analyzed, the top network found by IPA was "Cardiovascular System Development" $($ score $=11) .11$ proteins of the 115 regulated proteins in aorta were part of this network. The graphical representation of the network is shown in Figure 3, in which the modulated proteins (located in the cell compartments) have been highlighted in color and indicated when HT and SEC differently modulated a protein (up or down-regulated).

We observed a significant increase of Hk2, Fabp5, Ldh proteins and a decrease of Akr1b1, Capn2, Gja1, Rac1, Ilk, Vcl and Kng1/Kng111 proteins after both treatments. Vim protein was up-regulated by HT treatment and down-regulated after SEC treatment. Some of these proteins (Kng1, Hk2, Gja1 and Rac1) were found by IPA to have a 
strong relation with specific cardiovascular system functions, which are listed in Table 4. These proteins were mainly related to cardiac functions in this tissue such as occlusion of blood vessel and proliferation of endothelial cells.

Other proteins implicated in the network and connected with the proteins detected in our study were: NF-кB, Hspb1, Prkce, Pten, Mapk14, Prkca, Nos2, Erk1/2, Pka, Akt, Pdpk1, Pak2, Pxn, Rhoa, Nos3, Casp3, Pik3r1, Dock7, Cav3, Agtr2, Slc2a4, Igf1r, Cav1 and Ctgf. As shown NF- $\kappa$ B complex and Akt appeared to be key proteins in the network.

\subsubsection{Heart tissue}

In the case of heart tissue, the top network found by IPA was "Cardiovascular System Development and Cancer" (score $=57$ ). 21 proteins of the 34 regulated proteins in heart were part of this network, which is represented in Figure 4.

The up-regulated proteins after HT and SEC treatments implicated in this network were Npm1, Fkbpla, Tuba4a, Arhgdia, Msn and Alpha tubulin proteins and the down-regulated were Por, Dlat, Dld, Cys, Cytochrome C and Magi 2 proteins (Figure 4). Some proteins, such as Hmgb1, Hbb, Actn4, Psma6, Dnm11, Map4 and Clic4, were down-regulated by HT treatment and up-regulated in response to SEC treatment. On the other hand, Samm50, Glrx3, Prep and Camk2d were up-regulated by HT treatment and down-regulated after SEC treatment. As in aorta, some of these proteins had a strong relation with specific cardiovascular system functions, which are listed in Table 4. Some of these proteins such as Camk2d, Fkbpla and Tuba4a, were related to cardiac functions and other proteins such as Dlat, Dld and Por were related to lipid metabolism. Other proteins implicated in the network were Ppil4, Nf-kB, estrogen receptor, Hsp90, Calcineurin proteins, Caspase, Akt, P38 Mapk, Pka, Cd3 and N-methyl-R-salsolinol. $\mathrm{NF}-\kappa \mathrm{B}$ complex also resulted in a pivotal position as in aorta network. 


\section{Discussion}

Under the hypothesis that VOO phenolic compounds could promote benefits in cardiovascular system by inducing changes in the heart and aorta protein levels, in the present study we performed a proteomic analysis of the aorta and heart tissues of healthy rats in response to a diet supplemented with HT to investigate the underlying molecular mechanism of HT and to identify potential target proteins in cardiovascular tissues. HT was administrated either as a pure molecule or through its complex occurring forms in VOO (SEC) at the same daily dose $(5 \mathrm{mg} / \mathrm{kg}$ rat weight) in order to investigate possible differences in the molecular mechanisms depending on the chemical structure administered.

\subsection{Aorta and heart proteome modulation by HT and SEC}

Proteomic analysis revealed that the heart and aorta proteome significantly changed after the administration of VOO phenolics compared to the control group, observing a clearer differentiation when diet was supplemented with SEC (Supporting information: Figure 1). As expected, most of the proteins were similarly modulated after SEC and HT and FC values did not exceed in most cases 2.5 -fold. The relatively low FC after the supplemented diets could be attributed to the healthy status of the animals. Previous studies have focused on the proteomic profiling of aorta diseased tissues in order to gain knowledge of the molecular events underlying pathological processes such as the atherosclerotic lesions [18]. However, based on the general consensus that VOO phenolic compounds have a protective role in the cardiovascular system [1], in this study we present the proteomic technique applied to healthy cardiovascular tissues as a novel approach to gain knowledge in the possible prevention mechanisms of these bioactive compounds. 
There are scarce data in the bibliography regarding the effect of olive phenols on the tissue proteome modulation and so far no studies have been performed with heart and aorta tissues. Only some studies performed in injured liver of rat or mice and the hepatic proteome analysis revealed that VOO phenolic compounds could have benefits against chronic liver injury and steatosis, which was attributed to the modulation of proteins related to antioxidant mechanisms [19-21]. In other studies, the effect of VOO on the plasma proteome during aging in rats was analyzed [22] and also the impact on the HDL protein cargo of the intake of VOO and two other phenol-enriched VOO in hypercholesterolemic subjects [23]. In both cases, a modulation of proteins related to cholesterol homeostasis, protection against oxidation and blood coagulation was observed.

When comparing HT and SEC, diet supplementation with SEC leaded to higher FC values. These differences could be attributed to the higher concentration of free HT detected in heart tissue after SEC diet (Table 1). In our previous work it was demonstrated that despite that HT and SEC were administered at the same dose (5 $\mathrm{mg} / \mathrm{kg}$ rat weight), the urinary recovery of HT metabolites was higher with SEC, indicating that the bioavailability of HT was more effective with the intake of the more complex structure as SEC (Lopez de las Hazas 2016; J Func Foods, submitted). Consequently, higher amounts of HT and HT metabolites were able to reach the target tissue (heart) and could have exerted a greater modulation of the proteome. These results highlight that the complementary information regarding the bioavailability and the tissue disposition of the phenolic metabolites is critical to understand and determine the bioactivity exerted in that tissue. Our results demonstrate that phenolic compounds were effectively absorbed and could reach target tissues such as heart. In accordance, in a previous study performed by our group demonstrated that the free HT at physiological 
concentrations and in a dose-dependent manner, could exert significant effects reducing adhesion molecules (vascular adhesion molecule-1, intracellular adhesion molecule-1, E-selectin and P-selectin) and in a chemokine (monocyte chemoattractant protein-1) in human aortic endothelial cells stimulated by tumor necrosis factor alpha-1 [24].

\subsection{Pathway analysis of common proteins modulated by HT and SEC}

In a first step, we analyzed in IPA the common proteins that were differentially expressed in the same direction after HT and SEC supplementation. From these results we highlight the potential upstream regulators that appeared to be implicated, which allowed us to identify the molecules upstream of the proteins that potentially explain the observed expression changes.

In the case of aorta, Myc, Myocd, Pias1, Yap1 and Srf appeared to be potentially implicated in the modulated pathways. All these proteins have been shown to play a role in proliferative vascular disorders in vascular smooth muscle cells (VSMC) [25]. Specifically, Yap1, Myc and Myocd have been related in the modulation of VSMC phenotype in response to the environmental stimuli through a process characterized by an increased proliferation and migration [26]. Phenotypic switch of VSMC is one of the major cellular events underlying many VSMC-related pathological conditions, such as atherosclerosis.

In heart tissue, the top upstream regulators that appeared to be potentially implicated were E2f4 and PPAR- $\gamma$. The transcription factor E2f4 has been shown to act as an activator of cardiomyocyte proliferation, a required regulator for cardiac regeneration [27]. PPAR- $\gamma$ has been well recognized to be a central player participating in various biological responses, including lipid metabolism, inflammation, and cell proliferation, the underlying pathological processes of metabolic diseases and cancer [28]. So, the potentially implication of these upstream regulators in aorta and heart 
tissues in response to olive phenolic compounds provides insight into the molecular mechanisms underlying their protective action on cardiovascular alterations.

\subsection{Global network analysis after HT or SEC and its relation with Cardiovascular System}

The network analysis based on the whole expressed proteins after HT and SEC diets demonstrated that the top-scored networks were related to Cardiovascular System Development in both tissues (Figures 3 and 4), and specifically, some of the modulated proteins appeared to be involved in particular cardiac functions and lipid metabolism (Table 4). In the case of aorta (Figure 3), the proteins involved in the top-scored network were mainly related to several cardiac functions. One of the down-regulated proteins was T-kininogen 2 (-1,2-fold and -2,7-fold for HT and SEC respectively), involved in the occlusion of blood vessel and proliferation of endothelial cells. Kininogens are multifunctional proteins that act as precursor of kinins, small vasoactive peptides that promote endothelial cell proliferation through kinin receptors and its plasma levels have been related to inflammatory and aging processes in rats and humans [29]. In accordance with our results, T-kininogen precursor was significantly decreased after the intake of VOO compared with sunflower oil in rats [22]. Therefore, the decrease of T-kininogen 2 after intake of HT and SEC suggests that HT could contribute to the decline of inflammatory processes. Together with T-kininogen 2, Gap junction alpha-1 protein (Gja1), was also related to proliferation of endothelial cells, as well as with cardiogenesis and vasoconstriction of blood vessel and, in the same line, it was down-regulated after HT (-1,0-fold) and SEC (-1.7-fold) treatments.

Another relevant protein involved in the top-scored Cardiovascular System network in aorta was Rac1 (ras-related C3 botulinum toxin substrate 1), which was 
significantly down-regulated after HT (-1,0-fold) and SEC (-1,4-fold) diets and appeared to be implicated in the migration of endothelial cells and heart rate functions (Table 4). Rac1 is a small GTPase essential for the assembly and activation of NADPH oxidase. Several molecular and cellular studies have reported the involvement of Rac1 in different cardiovascular pathologies, such as vascular smooth muscle proliferation, atherosclerosis and endothelial dysfunction [30]. Also an increased activation of NADPH oxidase by Rac1 has also been reported in animals and humans after myocardial infarction and heart failure [30]. Due to all these findings, Rac1 has emerged as a new pharmacological target for the treatment of CVD [31]. Thus, our results suggest that its down-regulation after HT and SEC consumption could imply a cardio-protection effect.

Hexokinase-2 (HK2) also appeared to be one of the differentially expressed proteins (1,3-fold for HT and 2,7-fold for SEC) related to the cardiovascular network in aorta and playing an important role in cell viability of cardiomyocytes and survival of ventricular myocytes (Table 4). HKs are multifunctional proteins that orchestrate metabolic, antioxidant and direct anti-cell death effects [32]. HK2 specifically has a role in shuttling glucose-6-phosphate to glycolysis and oxidative phosphorylation when bound to mitochondria [33]. Genetic reduction of HK2 levels in heterozygous HK2 knock-out mice increased susceptibility to ischemia/reperfusion injury [34] indicating its cardioprotective role. In this sense, HK2 also increased the cell viability of cultured ventricular myocytes [35]. Therefore, the overexpression of HK2 after HT and SEC administration suggests that HK2 could be an important protein target for HT. Hspe1 (up-regulated by HT 1,1-fold and SEC 2,5-fold) was also related to cardiac necrosis/cell death observed by previous studies in which its up-regulation decreased apoptosis of cardiac myocytes from newborn rat [36]. 
In the same line of cardio-protection, heat shock $70 \mathrm{kDa}$ protein (Hspala) was down-regulated after both treatments (-1.0-fold for HT and -2.3-fold for SEC). Hspala plays a multiple role in cellular homeostasis and its level increases rapidly in response to various types of severe stress. In fact, it has been related to the development of atherosclerosis [37], and also seems to be a clinically useful biomarker for prediction of mortality in heart failure patients [38]. Apart from the implication of Hspla1 in the cardiovascular system, its overexpression has been linked to the development of some cancers, such as hepatocellular carcinoma, gastric cancers, colon cancers, breast cancers, and lung cancers, which led to its use as a prognostic marker for these cancers [39]. Circulating Hspala has been also recently stablished as a clinical marker of rheumatoid arthritis, used for its diagnosis and monitoring the disease activity [40]. Moreover, the over-expression of Annexin 2 (Anxa2), which was down-regulated after both diets (1,0-fold for HT and -1,4-fold for SEC), has been defined as a prognostic marker in certain cancers such as cholangiocarcinoma [41]. These results together with all the presented evidence, suggest that olive phenols not only might be able to modulate proteins related to the prevention of CVD, but could also exert a protector effect against cancer modulating some cancer-relevant proteins.

The network analysis in heart tissue revealed that the significantly expressed proteins were implicated in cardiac functions but also in the lipid metabolism. Fkbpla (peptidyl-prolyl cis-trans isomerase), which appeared to be related to heart failure, hypertrophy of left ventricle, congestive heart failure and systolic dysfunction, was upregulated 1.2-fold and 1,7-fold by HT and SEC, respectively. Previous studies show that mutant mice deficient in Fkbpla develop multiple abnormalities in cardiac structure, including lack of compaction and thin ventricular walls [42], suggesting that its upregulation could imply a positive effect preventing all these anomalies. In the same line, 
Calcium/calmodulin-dependent protein kinase type II subunit delta (Camk2d) was also modulated and it has been defined as a determinant of clinically important heart disease phenotypes, and it has been suggested that its inhibition can be a highly selective approach for targeting adverse myocardial hypertrophy, dilation and dysfunction, in individuals with myocardial infarction [43].

Other down-regulated proteins in heart tissue (Por, Dlat and Dld) appeared to be related to lipid metabolism functions such as synthesis of acetyl-CoA, fatty acid metabolism and synthesis of lipids. In particular, NADPH-cytrochome p450 reductase (Por) is an enzyme that is required for electron transfer to cytochrome P450 enzymes and plays a major role in regulating lipid homeostasis. On the other hand, Dlat and Dld play a role in energy metabolism, specifically in the pyruvate metabolism.

Another related protein that appeared to be down-regulated was Cythocrome c (Cycs), a component of the electron transport chain in mitochondria involved in initiation of apoptosis. Cycs release in cardiomyocytes has been attributed to many mechanisms including ROS generation, cardiolipin peroxidation, and $\mathrm{Ca}^{2+}$ overload in the mitochondria and therefore, if the release of Cytc could be inhibited, apoptosis could be prevented, slowing the disease progression or limiting neurologic damage after trauma [44].

Interpreting the findings of the present proteomic study is mitigated by a limited understanding of the individual role of implicated proteins within the tissue. The differentially expressed proteins have been localized to specific signaling pathways or networks but the interplay between pathways is complex and incompletely understood. Nevertheless, the findings of the present study clearly revealed that HT and SEC may 
play a pivotal role in the Cardiovascular System through the modulation of several proteins.

In conclusion, proteomic analysis revealed that the heart and aorta proteome significantly changed after the diet supplementation with HT and SEC compared to the control group. As expected, most of the proteins were similarly modulated after HT and SEC, and FC values did not exceed in most cases 2.5 fold, which was attributed to the healthy status of the animals. The network analysis involving the differentially expressed proteins revealed that the top-scored networks were related to cardiovascular system in both aorta and heart tissues. Specifically, our results demonstrated that HT and SEC are able to positively regulate the expression of relevant proteins (Rac1, Tkininogen 2, Gja1 and Hsp1a1) in aorta tissue related to atherosclerotic processes such as proliferation and migration of endothelial cells and occlusion of blood vessels. In heart, the more relevant modulated proteins (Camk2d and Fkbp1a) were related to cardiac functions such as heart failure.

Moreover, other prognostic markers for some cancers, Hspla1 and Anxa2, were modulated after HT and SEC treatments, suggesting that olive phenols could also exert a protector effect against cancer.

Diet supplementation with SEC demonstrated higher FC values which was attributed to the higher concentration of HT detected in heart tissue as consequence of the more effective bioavailability and heart tissue disposition. These results suggest that SEC, the main phenolics present in VOO, could have a higher cardio-protective effect than free HT.

In this study we present the proteomic technique applied to healthy cardiovascular tissues as a novel approach to gain knowledge in the possible root causes 
for the VOO phenol protective effects in cardiovascular system. Nevertheless further studies are needed to asses SEC or HT supplementation in animals with a cardiovascular pathology.

\section{Acknowledgements}

This study was supported by the Spanish Ministry of Education and Science, The MEFOPC Project (AGL2012-40144-C03-03 and AGL2012-40144-C03-02) and by the University of Lleida through the M-C. López de las Hazas grant.

The authors have declared no conflict of interest.

\section{Figure legends}

Figure 1. Experimental workflow chart.

Figure 2. Venn diagram of aorta and heart tissue. Venn diagram showing intersections of proteins differentially expressed in aorta A) or heart B) tissue of healthy rats comparing HT versus control and SEC versus control group. Red color indicates up-regulated proteins and green color indicates down-regulated proteins.

Figure 3. Aorta Cardiovascular System Network after HT or SEC treatments. Interaction between the proteins differentially expressed in aorta after HT or SEC treatments and other important proteins related to the same network. HT or SEC are represented in red or green color if the protein is up- or down-regulated respectively after HT or SEC treatments.

\section{Figure 4. Heart Cardiovascular System Network after HT or SEC treatments.} Interaction between the proteins differentially expressed in heart after HT or SEC treatments and other important proteins related to the same network. HT or SEC are 
represented in red or green color if the protein is up- or down-regulated respectively after HT or SEC treatments.

Supporting information: Figure 1. Principal component analysis (PCA) for differentially expressed proteins of $\mathbf{A}$ ) aorta tissue or $\mathbf{B}$ ) heart tissue samples of control $(\boldsymbol{\bullet})$, HT $(\boldsymbol{\Delta})$ or $\operatorname{SEC}(\bullet)$ group.

\section{References}

[1] Martín-Peláez, S., Covas, M.I., Fitó, M., Kušar, A., Pravst, I., Health effects of olive oil polyphenols: recent advances and possibilities for the use of health claims. Mol. Nutr. Food Res. 2013, 57, 760-71.

[2] Hu, T., He, X.-W., Jiang, J.-G., Xu, X.-L., Hydroxytyrosol and its potential therapeutic effects. J. Agric. Food Chem. 2014, 62, 1449-55.

[3] Cicerale, S., Lucas, L., Keast, R., Biological activities of phenolic compounds present in virgin olive oil. Int. J. Mol. Sci. 2010, 11, 458-79.

[4] Sofi, F., Abbate, R., Gensini, G.F., Casini, A., Accruing evidence on benefits of adherence to the Mediterranean diet on health: an updated systematic review and meta-analysis. Am. J. Clin. Nutr. 2010, 92, 1189-96.

[5] Meydani, M., in:, Ann. N. Y. Acad. Sci., vol. 928, 2001, pp. 226-235.

[6] Oda, T., Matsumoto, K.-I., Proteomic analysis in cardiovascular research. Surg. Today 2015.

[7] Anderson, L., Candidate-based proteomics in the search for biomarkers of cardiovascular disease. J. Physiol. 2005, 563, 23-60.

[8] Rangel-Zúñiga, O.A., Camargo, A., Marin, C., Peña-Orihuela, P., et al., Proteome from patients with metabolic syndrome is regulated by quantity and quality of dietary lipids. BMC Genomics 2015, 16, 509.

[9] de Roos, B., McArdle, H.J., Proteomics as a tool for the modelling of biological processes and biomarker development in nutrition research. Br. J. Nutr. 2008, 99 Suppl 3, S66-71.

[10] Kaga, E., Karademir, B., Baykal, A.T., Ozer, N.K., Identification of differentially expressed proteins in atherosclerotic aorta and effect of vitamin E. $J$. Proteomics 2013, 92, 260-73.

[11] Joumard-Cubizolles, L., Gladine, C., Gérard, N., Chambon, C., et al., Proteomic analysis of aorta of LDLR - $/-$ mice given omega-3 fatty acids reveals modulation of energy metabolism and oxidative stress pathway. Eur. J. Lipid Sci. Technol. 2013, 115, 1492-1498.

[12] Dekkers, D.H.W., Bezstarosti, K., Gurusamy, N., Luijk, K., et al., Identification by a differential proteomic approach of the induced stress and redox proteins by resveratrol in the normal and diabetic rat heart. J. Cell. Mol. Med. 2008, 12, $1677-89$. 
[13] Sabe, A.A., Sadek, A.A., Elmadhun, N.Y., Dalal, R.S., et al., Investigating the effects of resveratrol on chronically ischemic myocardium in a swine model of metabolic syndrome: a proteomics analysis. J. Med. Food 2015, 18, 60-6.

[14] Oda, T., Matsumoto, K.-I., Proteomic analysis in cardiovascular research. Surg. Today 2015.

[15] Suárez, M., Romero, M.-P., Ramo, T., Macià, A., Motilva, M.-J., Methods for preparing phenolic extracts from olive cake for potential application as food antioxidants. J. Agric. Food Chem. 2009, 57, 1463-72.

[16] Serra, A., Rubió, L., Borràs, X., Macià, A., et al., Distribution of olive oil phenolic compounds in rat tissues after administration of a phenolic extract from olive cake. Mol. Nutr. Food Res. 2012, 56, 486-96.

[17] D’Angelo, S., Manna, C., Migliardi, V., Mazzoni, O., et al., Pharmacokinetics and metabolism of hydroxytyrosol, a natural antioxidant from olive oil. Drug Metab. Dispos. 2001, 29, 1492-1498.

[18] Xu, J., Jüllig, M., Middleditch, M.J., Cooper, G.J.S., Modelling atherosclerosis by proteomics: Molecular changes in the ascending aortas of cholesterol-fed rabbits. Atherosclerosis 2015, 242, 268-76.

[19] Wang, H., Sit, W.-H., Tipoe, G.L., Wan, J.M.-F., Differential protective effects of extra virgin olive oil and corn oil in liver injury: A proteomic study. Food Chem. Toxicol. 2014, 74, 131-138.

[20] Arbones-Mainar, J.M., Ross, K., Rucklidge, G.J., Reid, M., et al., Extra virgin olive oils increase hepatic fat accumulation and hepatic antioxidant protein levels in APOE-/- mice. J. Proteome Res. 2007, 6, 4041-54.

[21] Rodríguez-Gutiérrez, G., Duthie, G.G., Wood, S., Morrice, P., et al., Alperujo extract, hydroxytyrosol, and 3,4-dihydroxyphenylglycol are bioavailable and have antioxidant properties in vitamin E-deficient rats--a proteomics and network analysis approach. Mol. Nutr. Food Res. 2012, 56, 1137-47.

[22] Santos-González, M., López-Miranda, J., Pérez-Jiménez, F., Navas, P., Villalba, J.M., Dietary oil modifies the plasma proteome during aging in the rat. Age (Dordr). 2012, 34, 341-58.

[23] Pedret, A., Catalán, Ú., Fernández-Castillejo, S., Farràs, M., et al., Impact of Virgin Olive Oil and Phenol-Enriched Virgin Olive Oils on the HDL Proteome in Hypercholesterolemic Subjects: A Double Blind, Randomized, Controlled, Cross-Over Clinical Trial (VOHF Study). PLoS One 2015, 10, e0129160.

[24] Catalán, Ú., López de Las Hazas, M.-C., Rubió, L., Fernández-Castillejo, S., et al., Protective effect of hydroxytyrosol and its predominant plasmatic human metabolites against endothelial dysfunction in human aortic endothelial cells. Mol. Nutr. Food Res. 2015.

[25] Ledee, D., Smith, L., Bruce, M., Kajimoto, M., et al., c-Myc Alters Substrate Utilization and O-GlcNAc Protein Posttranslational Modifications without Altering Cardiac Function during Early Aortic Constriction. PLoS One 2015, 10, $\mathrm{e} 0135262$.

[26] Owens, G.K., Kumar, M.S., Wamhoff, B.R., Molecular regulation of vascular smooth muscle cell differentiation in development and disease. Physiol. Rev. 2004, 84, 767-801. 
[27] van Amerongen, M.J., Diehl, F., Novoyatleva, T., Patra, C., Engel, F.B., E2F4 is required for cardiomyocyte proliferation. Cardiovasc. Res. 2010, 86, 92-102.

[28] Kim, J.-H., Song, J., Park, K.W., The multifaceted factor peroxisome proliferator-activated receptor $\gamma(\mathrm{PPAR} \gamma)$ in metabolism, immunity, and cancer. Arch. Pharm. Res. 2015, 38, 302-12.

[29] Pérez, V., Leiva-Salcedo, E., Acuña-Castillo, C., Aravena, M., et al., Tkininogen induces endothelial cell proliferation. Mech. Ageing Dev. 2006, 127, 282-9.

[30] Carrizzo, A., Forte, M., Lembo, M., Formisano, L., et al., Rac-1 as a new therapeutic target in cerebro-and cardio-vascular diseases. Curr. Drug Targets 2014, 15, 1231-1246.

[31] Ferri, N., Contini, A., Bernini, S.K., Corsini, A., Role of small GTPase protein Rac1 in cardiovascular diseases: development of new selective pharmacological inhibitors. J. Cardiovasc. Pharmacol. 2013, 62, 425-35.

[32] Calmettes, G., Ribalet, B., John, S., Korge, P., et al., Hexokinases and cardioprotection. J. Mol. Cell. Cardiol. 2015, 78, 107-15.

[33] John, S., Weiss, J.N., Ribalet, B., Subcellular localization of hexokinases I and II directs the metabolic fate of glucose. PLoS One 2011, 6, e17674.

[34] Smeele, K.M.A., Southworth, R., Wu, R., Xie, C., et al., Disruption of hexokinase II-mitochondrial binding blocks ischemic preconditioning and causes rapid cardiac necrosis. Circ. Res. 2011, 108, 1165-9.

[35] Roberts, D.J., Tan-Sah, V.P., Smith, J.M., Miyamoto, S., Akt phosphorylates HK-II at Thr-473 and increases mitochondrial HK-II association to protect cardiomyocytes. J. Biol. Chem. 2013, 288, 23798-806.

[36] Lin, K.M., Lin, B., Lian, I.Y., Mestril, R., et al., Combined and individual mitochondrial HSP60 and HSP10 expression in cardiac myocytes protects mitochondrial function and prevents apoptotic cell deaths induced by simulated ischemia-reoxygenation. Circulation 2001, 103, 1787-92.

[37] Xu, Q., Metzler, B., Jahangiri, M., Mandal, K., Molecular chaperones and heat shock proteins in atherosclerosis. Am. J. Physiol. Heart Circ. Physiol. 2012, 302, H506-14.

[38] Jenei, Z.M., Gombos, T., Förhécz, Z., Pozsonyi, Z., et al., Elevated extracellular HSP70 (HSPA1A) level as an independent prognostic marker of mortality in patients with heart failure. Cell Stress Chaperones 2013, 18, 809-13.

[39] Wang, X., Wang, Q., Lin, H., Li, S., et al., HSP72 and gp96 in gastroenterological cancers. Clin. Chim. Acta. 2013, 417, 73-9.

[40] Najafizadeh, S.R., Ghazizadeh, Z., Nargesi, A.A., Mahdavi, M., et al., Analysis of serum heat shock protein 70 (HSPA1A) concentrations for diagnosis and disease activity monitoring in patients with rheumatoid arthritis. Cell Stress Chaperones 2015, 20, 537-43.

[41] Wang, A.-G., Yoon, S.Y., Oh, J.-H., Jeon, Y.-J., et al., Identification of intrahepatic cholangiocarcinoma related genes by comparison with normal liver tissues using expressed sequence tags. Biochem. Biophys. Res. Commun. 2006, $345,1022-32$.

[42] Towbin, J.A., Lorts, A., Jefferies, J.L., Left ventricular non-compaction 
2

cardiomyopathy. Lancet 2015, 386, 813-825.

[43] Kreusser, M.M., Lehmann, L.H., Keranov, S., Hoting, M.-O., et al., Cardiac CaM Kinase II genes $\delta$ and $\gamma$ contribute to adverse remodeling but redundantly inhibit calcineurin-induced myocardial hypertrophy. Circulation 2014, 130, 1262-73.

[44] Hüttemann, M., Pecina, P., Rainbolt, M., Sanderson, T.H., et al., The multiple functions of cytochrome $\mathrm{c}$ and their regulation in life and death decisions of the mammalian cell: From respiration to apoptosis. Mitochondrion 2011, 11, 369-81. 
Table 1. Concentration (nmols/g fresh tissue) of free hydroxytyrosol and the main metabolite, hydroxytyrosol-3- $O$-sulfate, detected in heart tissue after the diet supplementation (21 days) with $5 \mathrm{mg} / \mathrm{kg}$ weight rat/day of hydroytyrosol (HT) or secoiridois (SEC).

\begin{tabular}{lccc}
\hline & $\begin{array}{c}\text { Control } \\
(\mathrm{n}=4)\end{array}$ & $\begin{array}{c}\text { SEC } \\
(\mathrm{n}=4)\end{array}$ & $\begin{array}{c}\text { HT } \\
(\mathrm{n}=4)\end{array}$ \\
\hline Free hydroxytyrosol & $5.78(0.02)^{\mathrm{a}}$ & $19.6(1.56)^{\mathrm{c}}$ & $8.75(0.82)^{\mathrm{b}}$ \\
Hydroxytyrosol-3-O-sulfate & n.d. & n.d. & $0.52(0.18)^{\mathrm{a}}$ \\
\hline
\end{tabular}

n.d.: non detectable

a. b. c indicates significant differences among treatments in the same row at the $95.0 \%$ level of confidence.

Results are expressed as mean (standard deviation; SD) 
Table 2. 115 significant proteins differentially expressed in aortic tissue of healthy rats after HT or SEC treatments.

1

2

3

4

5

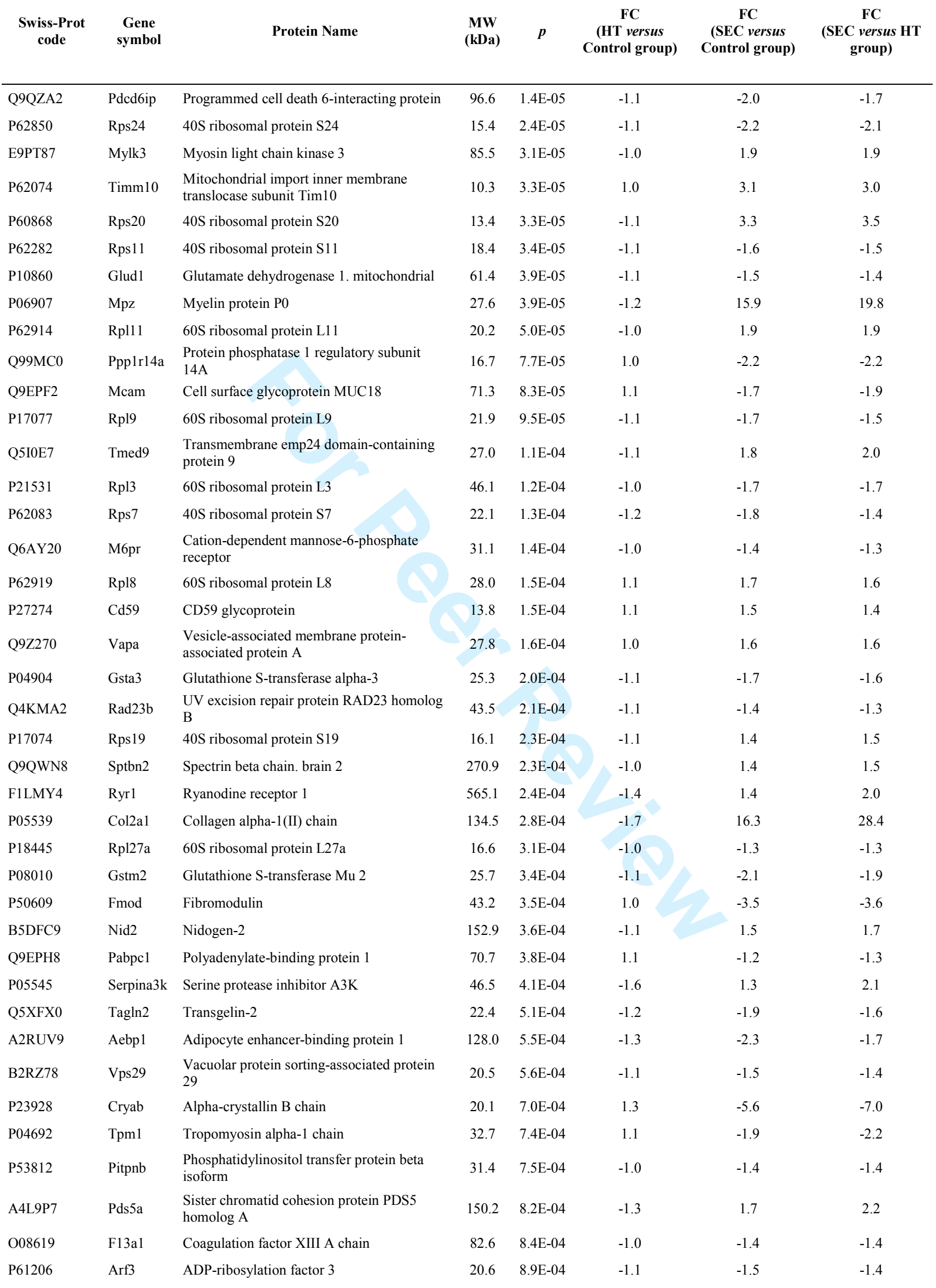




\begin{tabular}{|c|c|c|c|c|c|c|c|}
\hline Q63357 & Myold & Unconventional myosin-Id & 116.0 & $8.9 \mathrm{E}-04$ & -1.1 & -2.1 & -1.8 \\
\hline P16257 & Tspo & Translocator protein & 18.9 & $9.9 \mathrm{E}-04$ & -1.0 & 1.6 & 1.6 \\
\hline P70470 & Lypla 1 & Acyl-protein thioesterase 1 & 24.7 & $1.1 \mathrm{E}-03$ & -1.1 & 1.4 & 1.5 \\
\hline Q4V8C3 & Eml1 & $\begin{array}{l}\text { Echinoderm microtubule-associated protein- } \\
\text { like } 1\end{array}$ & 89.7 & $1.1 \mathrm{E}-03$ & -1.1 & -1.7 & -1.6 \\
\hline P24050 & Rps5 & $40 \mathrm{~S}$ ribosomal protein $\mathrm{S} 5$ & 22.9 & $1.2 \mathrm{E}-03$ & -1.0 & -1.2 & -1.1 \\
\hline P0C5E3 & Palld & Palladin (Fragment) & 66.7 & $1.4 \mathrm{E}-03$ & -1.0 & -1.5 & -1.5 \\
\hline Q08290 & Cnn1 & Calponin-1 & 33.3 & $1.4 \mathrm{E}-03$ & 1.1 & -3.8 & -4.3 \\
\hline Q07439 & Hspa1a & Heat shock $70 \mathrm{kDa}$ protein $1 \mathrm{~A} / 1 \mathrm{~B}$ & 70.1 & $1.4 \mathrm{E}-03$ & -1.0 & -2.3 & -2.2 \\
\hline P40307 & Psmb2 & Proteasome subunit beta type- 2 & 22.9 & $1.5 \mathrm{E}-03$ & -1.1 & -1.4 & -1.3 \\
\hline P05544 & Serpina31 & Serine protease inhibitor A3L & 46.2 & $1.5 \mathrm{E}-03$ & -1.6 & 1.2 & 1.9 \\
\hline P63039 & Hspd1 & $60 \mathrm{kDa}$ heat shock protein. mitochondrial & 60.9 & $1.6 \mathrm{E}-03$ & -1.1 & 1.5 & 1.7 \\
\hline P08932 & $\mathrm{N} / \mathrm{A}$ & T-kininogen 2 & 47.7 & $1.7 \mathrm{E}-03$ & -1.2 & -2.7 & -2.3 \\
\hline Q9QXQ0 & Actn 4 & Alpha-actinin-4 & 104.8 & $1.8 \mathrm{E}-03$ & -1.1 & -1.7 & -1.6 \\
\hline P58775 & Tpm2 & Tropomyosin beta chain & 32.8 & $1.8 \mathrm{E}-03$ & -1.1 & -2.1 & -1.9 \\
\hline D3Z9R8 & Mp6 & $6.8 \mathrm{kDa}$ mitochondrial proteolipid & 6.9 & $1.8 \mathrm{E}-03$ & -1.0 & -4.1 & -4.0 \\
\hline P24054 & Sparcl1 & SPARC-like protein 1 & 70.6 & $1.8 \mathrm{E}-03$ & -1.4 & -2.8 & -2.0 \\
\hline P08082 & Cltb & Clathrin light chain B & 25.1 & $2.0 \mathrm{E}-03$ & -1.1 & -1.7 & -1.6 \\
\hline Q9Z1P2 & Actn1 & Alpha-actinin-1 & 102.9 & $2.1 \mathrm{E}-03$ & -1.1 & -2.5 & -2.2 \\
\hline Q01129 & Den & Decorin & 39.8 & $2.1 \mathrm{E}-03$ & -1.1 & -1.4 & -1.3 \\
\hline Q9R063 & $\operatorname{Prdx} 5$ & Peroxiredoxin-5. mitochondrial & 22.2 & $2.2 \mathrm{E}-03$ & 1.1 & 1.6 & 1.5 \\
\hline P51886 & Lum & Lumican & 38.3 & $2.3 \mathrm{E}-03$ & -1.1 & -1.6 & -1.4 \\
\hline Q63862 & Myh11 & Myosin-11 (Fragments) & 152.4 & $2.5 \mathrm{E}-03$ & -1.1 & -1.6 & -1.5 \\
\hline P61983 & Ywhag & $14-3-3$ protein gamma & 28.3 & $2.6 \mathrm{E}-03$ & 1.0 & 1.5 & 1.5 \\
\hline P14046 & A1i3 & Alpha-1-inhibitor 3 & 163.7 & $2.7 \mathrm{E}-03$ & -1.2 & -1.9 & -1.6 \\
\hline P31232 & Tagln & Transgelin & 22.6 & $2.8 \mathrm{E}-03$ & -1.1 & -2.0 & -1.8 \\
\hline Q62745 & $\mathrm{Cd} 81$ & CD81 antigen & 25.9 & $2.9 \mathrm{E}-03$ & -1.1 & -2.0 & -1.8 \\
\hline Q68FT1 & Coq9 & $\begin{array}{l}\text { Ubiquinone biosynthesis protein COQ9. } \\
\text { mitochondrial }\end{array}$ & 35.1 & $3.0 \mathrm{E}-03$ & 1.1 & 2.1 & 1.9 \\
\hline P16975 & Sparc & SPARC & 34.3 & $3.1 \mathrm{E}-03$ & -1.1 & -3.0 & -2.8 \\
\hline P41123 & Rpl13 & 60 S ribosomal protein $\mathrm{L} 13$ & 24.3 & $3.1 \mathrm{E}-03$ & -1.1 & -2.0 & -1.9 \\
\hline Q923W4 & Hdgfrp3 & $\begin{array}{l}\text { Hepatoma-derived growth factor-related } \\
\text { protein } 3\end{array}$ & 22.4 & $3.1 \mathrm{E}-03$ & -1.2 & -1.5 & -1.3 \\
\hline Q9EST6 & Anp32b & $\begin{array}{l}\text { Acidic leucine-rich nuclear phosphoprotein } \\
32 \text { family member B }\end{array}$ & 31.0 & $3.2 \mathrm{E}-03$ & 1.0 & -1.4 & -1.4 \\
\hline P08050 & Gjal & Gap junction alpha-1 protein & 43.0 & $3.5 \mathrm{E}-03$ & -1.0 & -1.7 & -1.7 \\
\hline P62278 & Rps13 & $40 \mathrm{~S}$ ribosomal protein $\mathrm{S} 13$ & 17.2 & $3.7 \mathrm{E}-03$ & 1.1 & -1.3 & -1.3 \\
\hline Q4QQT4 & Ppp2r1b & $\begin{array}{l}\text { Serine/threonine-protein phosphatase } 2 \mathrm{~A} 65 \\
\mathrm{kDa} \text { regulatory subunit A beta isoform }\end{array}$ & 66.0 & $3.7 \mathrm{E}-03$ & 1.2 & 1.6 & 1.3 \\
\hline Q7M0E3 & Dstn & Destrin & 18.5 & $3.8 \mathrm{E}-03$ & -1.1 & -2.1 & -1.8 \\
\hline P10111 & Ppia & Peptidyl-prolyl cis-trans isomerase A & & $3.8 \mathrm{E}-03$ & -1.1 & -1.5 & -1.3 \\
\hline P13635 & $\mathrm{Cp}$ & Ceruloplasmin & 120.8 & $3.9 \mathrm{E}-03$ & -1.4 & -1.6 & -1.2 \\
\hline D3Z8E6 & Camsap1 & $\begin{array}{l}\text { Calmodulin-regulated spectrin-associated } \\
\text { protein } 1\end{array}$ & 178.4 & $4.1 \mathrm{E}-03$ & -1.1 & -1.6 & -1.4 \\
\hline P85972 & $\mathrm{Vcl}$ & Vinculin & 116.5 & $4.3 \mathrm{E}-03$ & -1.1 & -1.6 & -1.4 \\
\hline Q4V9H5 & Phf2011 & PHD finger protein 20 -like protein 1 & 114.0 & $4.5 \mathrm{E}-03$ & 1.0 & 2.0 & 1.9 \\
\hline Q4V7C7 & Actr3 & Actin-related protein 3 & 47.3 & $4.6 \mathrm{E}-03$ & -1.2 & -1.5 & -1.3 \\
\hline Q8VIF7 & Selenbp1 & Selenium-binding protein 1 & 52.5 & $4.7 \mathrm{E}-03$ & -1.1 & -1.4 & -1.3 \\
\hline Q62812 & Myh9 & Myosin-9 & 226.2 & $4.9 \mathrm{E}-03$ & -1.1 & -1.5 & -1.4 \\
\hline Q0ZHH6 & Atl3 & Atlastin-3 & 60.5 & $5.0 \mathrm{E}-03$ & -1.1 & -1.4 & -1.2 \\
\hline Q99J82 & Ilk & Integrin-linked protein kinase & 51.3 & $5.2 \mathrm{E}-03$ & -1.1 & -1.8 & -1.6 \\
\hline Q62908 & Csrp2 & Cysteine and glycine-rich protein 2 & 20.9 & $5.2 \mathrm{E}-03$ & -1.2 & -2.2 & -1.9 \\
\hline
\end{tabular}




\begin{tabular}{|c|c|c|c|c|c|c|c|}
\hline P55053 & Fabp5 & Fatty acid-binding protein. epidermal & 15.0 & $5.3 \mathrm{E}-03$ & 1.0 & 2.5 & 2.4 \\
\hline Q63610 & Tpm3 & Tropomyosin alpha-3 chain & 29.0 & $5.3 \mathrm{E}-03$ & 1.1 & -1.7 & -1.8 \\
\hline P11884 & Aldh2 & Aldehyde dehydrogenase. mitochondrial & 56.5 & $5.3 \mathrm{E}-03$ & -1.1 & -1.6 & -1.4 \\
\hline Q9QYP2 & Celsr2 & $\begin{array}{l}\text { Cadherin EGF LAG seven-pass G-type } \\
\text { receptor } 2 \text { (Fragment) }\end{array}$ & 233.3 & $5.4 \mathrm{E}-03$ & -1.2 & -3.0 & -2.5 \\
\hline Q9JHY2 & Sfxn3 & Sideroflexin-3 & 35.4 & $5.6 \mathrm{E}-03$ & -1.2 & -1.9 & -1.6 \\
\hline B2GUZ5 & Capza1 & F-actin-capping protein subunit alpha-1 & 32.9 & $5.8 \mathrm{E}-03$ & -1.1 & -1.6 & -1.5 \\
\hline B5DEH2 & Erlin2 & Erlin-2 & 37.7 & $6.1 \mathrm{E}-03$ & -1.1 & 1.4 & 1.4 \\
\hline P48037 & Anxa6 & Annexin A6 & 75.7 & $6.4 \mathrm{E}-03$ & -1.0 & -1.3 & -1.2 \\
\hline Q6RUV5 & Rac1 & Ras-related $\mathrm{C} 3$ botulinum toxin substrate 1 & 21.4 & $6.5 \mathrm{E}-03$ & -1.0 & -1.4 & -1.3 \\
\hline Q9Z1B2 & Gstm5 & Glutathione S-transferase Mu 5 & 26.6 & $6.6 \mathrm{E}-03$ & -1.1 & -1.5 & -1.3 \\
\hline P54311 & Gnb1 & $\begin{array}{l}\text { Guanine nucleotide-binding protein } \\
G(I) / G(S) / G(T) \text { subunit beta-1 }\end{array}$ & 37.4 & $6.6 \mathrm{E}-03$ & -1.1 & -1.5 & -1.3 \\
\hline P45592 & Cfl1 & Cofilin-1 & 18.5 & $6.6 \mathrm{E}-03$ & -1.1 & -1.6 & -1.5 \\
\hline P62271 & Rps 18 & $40 \mathrm{~S}$ ribosomal protein $\mathrm{S} 18$ & 17.7 & $6.6 \mathrm{E}-03$ & -1.0 & -1.7 & -1.7 \\
\hline Q6IRK9 & Pgcp & Plasma glutamate carboxypeptidase & 52.0 & $6.8 \mathrm{E}-03$ & -1.0 & 1.8 & 1.8 \\
\hline P04642 & Ldha & L-lactate dehydrogenase A chain & 36.4 & $7.0 \mathrm{E}-03$ & 1.1 & 1.9 & 1.7 \\
\hline P41562 & Idh1 & $\begin{array}{l}\text { Isocitrate dehydrogenase [NADP] } \\
\text { cytoplasmic }\end{array}$ & 46.7 & $7.0 \mathrm{E}-03$ & -1.1 & -1.3 & -1.2 \\
\hline P27881 & $\mathrm{Hk} 2$ & Hexokinase-2 & 102.5 & 7.1E-03 & 1.3 & 2.7 & 2.0 \\
\hline P50503 & St13 & Hsc70-interacting protein & 41.3 & 7.2E-03 & 1.0 & -1.8 & -1.8 \\
\hline P62828 & Ran & GTP-binding nuclear protein Ran & 24.4 & 7.3E-03 & -1.0 & 1.3 & 1.3 \\
\hline P31000 & Vim & Vimentin & 53.7 & 7.4E-03 & 1.0 & -1.9 & -1.9 \\
\hline Q62667 & Mvp & Major vault protein & 95.7 & 7.4E-03 & -1.0 & 1.4 & 1.4 \\
\hline P85973 & Pnp & Purine nucleoside phosphorylase & 32.3 & 7.6E-03 & -1.2 & -1.5 & -1.3 \\
\hline Q03626 & Mug1 & Murinoglobulin-1 & 165.2 & 7.6E-03 & -1.2 & -2.0 & -1.7 \\
\hline P26772 & Hspe1 & $10 \mathrm{kDa}$ heat shock protein. mitochondrial & 10.9 & $7.8 \mathrm{E}-03$ & 1.1 & 2.5 & 2.2 \\
\hline P20850 & Col9a1 & Collagen alpha-1(IX) chain (Fragment) & 31.2 & 7.9E-03 & -1.3 & -18.8 & -14.2 \\
\hline Q07936 & Anxa2 & Annexin A2 & 38.7 & $8.1 \mathrm{E}-03$ & -1.1 & -1.4 & -1.4 \\
\hline O70351 & Hsd17b10 & 3-hydroxyacyl-CoA dehydrogenase type-2 & 27.2 & $8.2 \mathrm{E}-03$ & 1.0 & 1.5 & 1.5 \\
\hline Q07009 & Capn2 & Calpain-2 catalytic subunit & 79.9 & $8.4 \mathrm{E}-03$ & -1.1 & -1.5 & -1.3 \\
\hline P07943 & Akr1b1 & Aldose reductase & 35.8 & $8.5 \mathrm{E}-03$ & -1.1 & -1.4 & -1.3 \\
\hline
\end{tabular}

HT, hydroxytyrosol; SEC, secoiridoids; MW, molecular weight; FC, fold change; N/A, not available.

The fold change is positive if the treatments are up-regulated and negative if they are down-regulated. comparing HT or SEC to control group and SEC to HT group. 
Table 3. 34 significant proteins differentially expressed in heart tissue of healthy rats after HT or SEC treatments.

\begin{tabular}{|c|c|c|c|c|c|c|c|}
\hline $\begin{array}{l}\text { Swiss-Prot } \\
\text { code }\end{array}$ & $\begin{array}{c}\text { Gene } \\
\text { symbol }\end{array}$ & Protein Name & $\begin{array}{c}\text { MW } \\
\text { (kDa) }\end{array}$ & $p$ & $\begin{array}{l}\text { FC } \\
\text { (HT versus } \\
\text { Control } \\
\text { group) }\end{array}$ & $\begin{array}{l}\text { FC } \\
\text { (SEC versus } \\
\text { Control } \\
\text { group) }\end{array}$ & $\begin{array}{l}\text { FC } \\
\text { (SEC versus } \\
\text { HT group) }\end{array}$ \\
\hline Q9Z0W7 & Clic4 & Chloride intracellular channel protein 4 & 28.60 & $3.3 \mathrm{E}-05$ & -1.1 & 1.4 & 1.5 \\
\hline P15865 & Hist1h1e & Histone H1.2 & 22.00 & $3.9 \mathrm{E}-05$ & -1.3 & 1.2 & 1.5 \\
\hline Q9QXQ0 & Actn4 & Alpha-actinin-4 & 104.80 & 4.0E-05 & -1.1 & 1.3 & 1.5 \\
\hline O35952 & Hagh & Hydroxyacylglutathione hydrolase. mitochondrial & 34.10 & $1.6 \mathrm{E}-04$ & 1.1 & 3.4 & 3.3 \\
\hline P0C0S7 & $\mathrm{H} 2 \mathrm{afz}$ & Histone H2A.Z & 13.50 & 2.7E-04 & -1.0 & -1.4 & -1.4 \\
\hline P43278 & H1fo & Histone H1.0 & 20.90 & $3.1 \mathrm{E}-04$ & -1.2 & 1.3 & 1.5 \\
\hline Q5XIF6 & Tuba4a & Tubulin alpha-4A chain & 49.90 & $3.5 \mathrm{E}-04$ & 1.1 & 1.2 & 1.1 \\
\hline P13084 & Npm1 & Nucleophosmin & 32.50 & $5.0 \mathrm{E}-04$ & 1.1 & 1.1 & 1.0 \\
\hline P15791 & Camk2d & $\begin{array}{l}\text { Calcium/calmodulin-dependent protein kinase type II } \\
\text { subunit delta }\end{array}$ & 60.00 & $5.6 \mathrm{E}-04$ & 1.4 & -1.4 & -2.0 \\
\hline P62076 & Timm13 & $\begin{array}{l}\text { Mitochondrial import inner membrane translocase } \\
\text { subunit Tim13 }\end{array}$ & 10.50 & $6.6 \mathrm{E}-04$ & -1.2 & -1.5 & -1.3 \\
\hline Q9JLZ1 & Glrx3 & Glutaredoxin-3 & 37.80 & $6.8 \mathrm{E}-04$ & 1.1 & -1.3 & -1.4 \\
\hline P00388 & Por & NADPH--cytochrome $\mathrm{P} 450$ reductase & 76.90 & 7.3E-04 & -1.3 & -1.4 & -1.1 \\
\hline Q5XI73 & Arhgdia & Rho GDP-dissociation inhibitor 1 & 23.40 & 7.7E-04 & 1.1 & 1.2 & 1.1 \\
\hline P83732 & Rpl24 & 60 S ribosomal protein L24 & 17.80 & $7.8 \mathrm{E}-04$ & -1.0 & 1.3 & 1.3 \\
\hline O70196 & Prep & Prolyl endopeptidase & 80.70 & $9.0 \mathrm{E}-04$ & 1.0 & -1.2 & -1.3 \\
\hline P62919 & Rpl8 & 60S ribosomal protein L8 & 28.00 & $1.0 \mathrm{E}-03$ & 1.2 & 1.3 & 1.1 \\
\hline Q6RJR6 & Rtn3 & Reticulon-3 & 101.50 & $1.1 \mathrm{E}-03$ & 1.0 & 1.2 & 1.2 \\
\hline P62329 & Tmsb4x & Thymosin beta- 4 & 5.00 & $1.2 \mathrm{E}-03$ & -1.2 & 1.9 & 2.3 \\
\hline P60901 & Psma6 & Proteasome subunit alpha type- 6 & 27.40 & $1.3 \mathrm{E}-03$ & -1.2 & 1.1 & 1.4 \\
\hline P11030 & Dbi & Acyl-CoA-binding protein & 10.00 & $1.4 \mathrm{E}-03$ & -1.3 & 1.1 & 1.4 \\
\hline Q562C7 & N/A & $\begin{array}{l}\text { Pumilio domain-containing protein KIAA0020 } \\
\text { homolog }\end{array}$ & 72.70 & $1.6 \mathrm{E}-03$ & -1.2 & 1.2 & 1.5 \\
\hline P63159 & Hmgb1 & High mobility group protein B1 & 24.90 & $1.7 \mathrm{E}-03$ & -1.0 & 1.4 & 1.4 \\
\hline Q6AXV4 & Samm50 & $\begin{array}{l}\text { Sorting and assembly machinery component } 50 \\
\text { homolog }\end{array}$ & 51.90 & $1.8 \mathrm{E}-03$ & 1.1 & -1.2 & -1.3 \\
\hline P62898 & Cycs & Cytochrome c. somatic & 11.60 & $1.8 \mathrm{E}-03$ & -1.1 & -1.3 & -1.2 \\
\hline O35763 & Msn & Moesin & 67.70 & $1.9 \mathrm{E}-03$ & 1.2 & 1.3 & 1.1 \\
\hline O88382 & Magi2 & $\begin{array}{l}\text { Membrane-associated guanylate kinase. WW and } \\
\text { PDZ domain-containing protein } 2\end{array}$ & 141.00 & $2.1 \mathrm{E}-03$ & -1.0 & -1.3 & -1.3 \\
\hline Q62658 & Fkbp1a & Peptidyl-prolyl cis-trans isomerase FKBP1A & 11.90 & $2.2 \mathrm{E}-03$ & 1.2 & 1.7 & 1.4 \\
\hline Q6P6R2 & Dld & Dihydrolipoyl dehydrogenase. mitochondrial & 54.00 & $2.2 \mathrm{E}-03$ & -1.1 & -1.1 & -1.0 \\
\hline Q6PCU8 & Ndufv3 & $\begin{array}{l}\text { NADH dehydrogenase [ubiquinone] flavoprotein } 3 . \\
\text { mitochondrial }\end{array}$ & 11.90 & $2.3 \mathrm{E}-03$ & -1.4 & 1.1 & 1.6 \\
\hline O35077 & Gpd1 & $\begin{array}{l}\text { Glycerol-3-phosphate dehydrogenase }[\mathrm{NAD}(+)] \text {, } \\
\text { cytoplasmic }\end{array}$ & 37.40 & $2.5 \mathrm{E}-03$ & -1.2 & -1.3 & -1.1 \\
\hline $\mathrm{O} 35303$ & Dnm11 & Dynamin-1-like protein & 83.90 & $2.5 \mathrm{E}-03$ & -1.0 & 1.2 & 1.2 \\
\hline P08461 & Dlat & $\begin{array}{l}\text { Dihydrolipoyllysine-residue acetyltransferase } \\
\text { component of pyruvate dehydrogenase complex, } \\
\text { mitochondrial }\end{array}$ & 67.10 & $2.5 \mathrm{E}-03$ & -1.1 & -1.1 & 1.0 \\
\hline P02091 & $\mathrm{Hbb}$ & Hemoglobin subunit beta-1 & 16.00 & 2.7E-03 & -1.1 & 2.2 & 2.5 \\
\hline Q5M7W5 & Map4 & Microtubule-associated protein 4 & 110.20 & 2.7E-03 & -1.2 & 1.0 & 1.2 \\
\hline
\end{tabular}

HT, hydroxytyrosol; SEC, secoiridoids; MW, molecular weight; FC, fold change; N/A, not available.

The fold change is positive if the treatments are up-regulated and negative if they are down-regulated. comparing HT or SEC to control group and SEC to HT group. 
Table 4. Functions and related proteins in aorta and heart tissue after HT or SEC treatments involved in the top-scored network: Cardiovascular System Development and Cancer

\begin{tabular}{|c|c|c|c|}
\hline \multirow{22}{*}{ Cardiac functions } & Cardiovascular System Functions & Aorta tissue proteins & Heart tissue proteins \\
\hline & Formation of Thrombus & Anxa2 & - \\
\hline & Occlusion of blood vessel & Kng1/Kng111 & - \\
\hline & Cell viability of cardiomyocytes & Hk2, Hspd1, Hk2 & - \\
\hline & Survival of ventricular myocytes & $\mathrm{Hk} 2$, & - \\
\hline & Proliferation of endothelial cells & Gja1, Kng1/Kng111 & - \\
\hline & Cardiogenesis & Gja1, Mylk3 & - \\
\hline & Vasoconstriction of blood vessel & Gja1, Hspa1a/Hspa1b & - \\
\hline & Migration of endothelial cell lines & Rac1 & - \\
\hline & Heart rate & Rac1, Tpm1 & - \\
\hline & Cell death of cardiomyocytes & Hspd1, Hspe1 & - \\
\hline & Apoptosis of cardiomyocytes & Hspd1, Hspe1 & - \\
\hline & Hypertrophy of cardiomyocytes & Cryab & Camk2d, H2afz, Glrx3 \\
\hline & Pericarditis & - & Tuba4a \\
\hline & Myocardial infarction & - & Tuba4a, Psma6 \\
\hline & Acute myocardial infarction & - & Tuba4a \\
\hline & Hypertrophy of heart & - & Camk2d, Fkbp1a, H2afz, Glrx3 \\
\hline & Severe heart failure & - & Camk2d \\
\hline & Failure of heart & - & Camk2d, Fkbp1a \\
\hline & Hypertrophy of left ventricle & - & Fkbpla \\
\hline & Congestive heart failure & - & Fkbpla \\
\hline & Systolic dysfunction & - & Fkbpla \\
\hline \multirow{17}{*}{ Lipid metabolism } & Synthesis of acetyl-coenzime A & - & Dlat, Dld, \\
\hline & Fatty acid metabolism & - & Dlat, Dld, Dbi, Hbb, Msn, Por \\
\hline & Acetylation of acetyl-coenzyme A & - & Dlat \\
\hline & Acetylation of dihydrolipoic acid & - & Dlat \\
\hline & Synthesis of lipid & - & Dlat, Dld, Dbi, Hbb, Por \\
\hline & Synthesis of fatty acid & - & Dlat, Dld, Hbb \\
\hline & Concentration of cholesterol & - & Dbi, Por, Arhgdia \\
\hline & Quantity fo very long chain fatty acid & - & Dbi \\
\hline & Quantity of farnesyl pyrophosphate & - & Por \\
\hline & Oxidation of testosterone & - & Por \\
\hline & Conversion of androstenedione & - & Por \\
\hline & Concentration of tretinoin & - & Por \\
\hline & Concentration of retinol & - & Por \\
\hline & Cytotoxicity of tacrolimus & - & Fkbpla \\
\hline & Oxidation of cardiolipin & - & Cycs \\
\hline & Oxidation of linoleic acid & - & Cycs \\
\hline & Binding of paclitaxel & - & Map4 \\
\hline
\end{tabular}




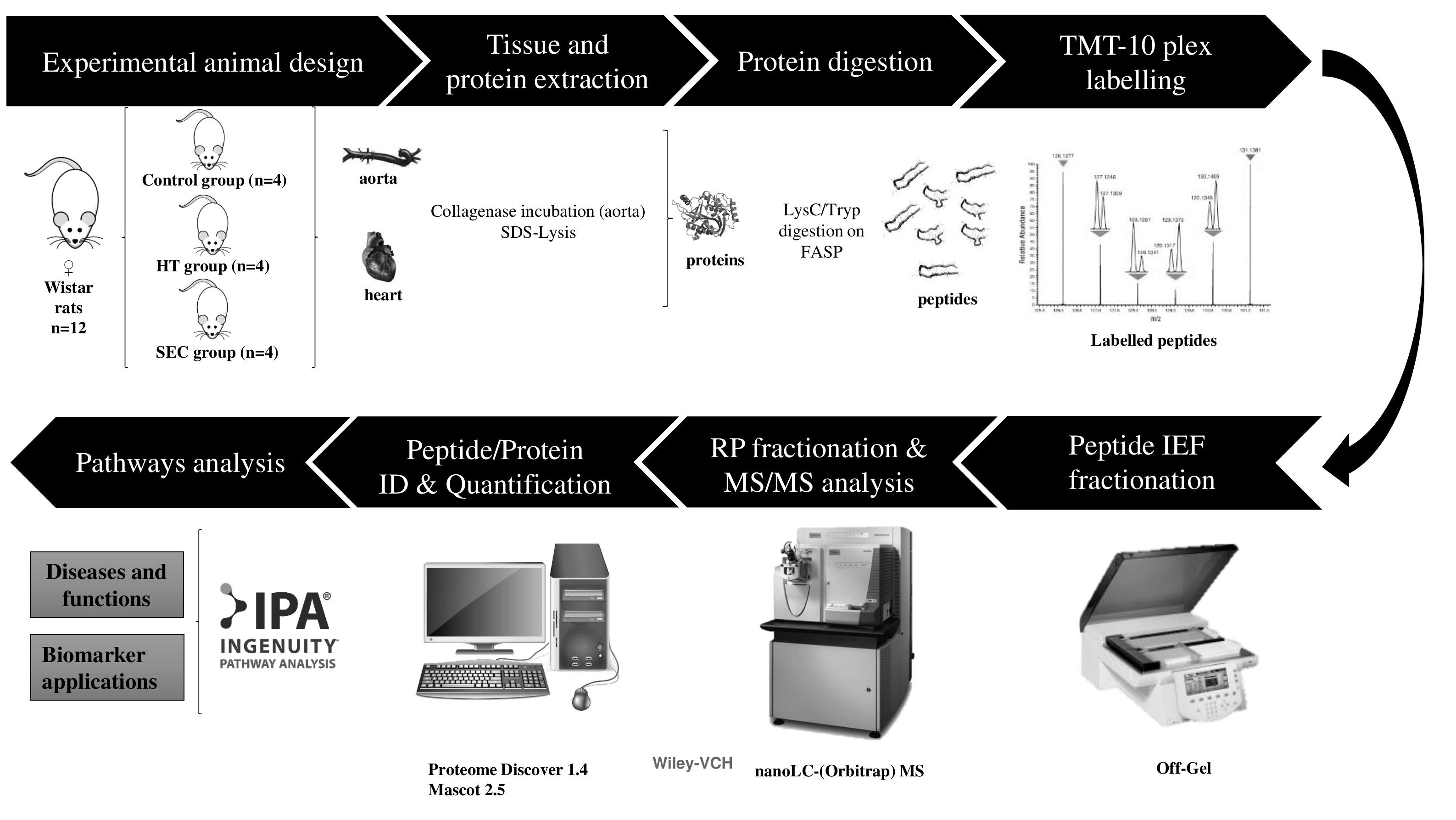


A

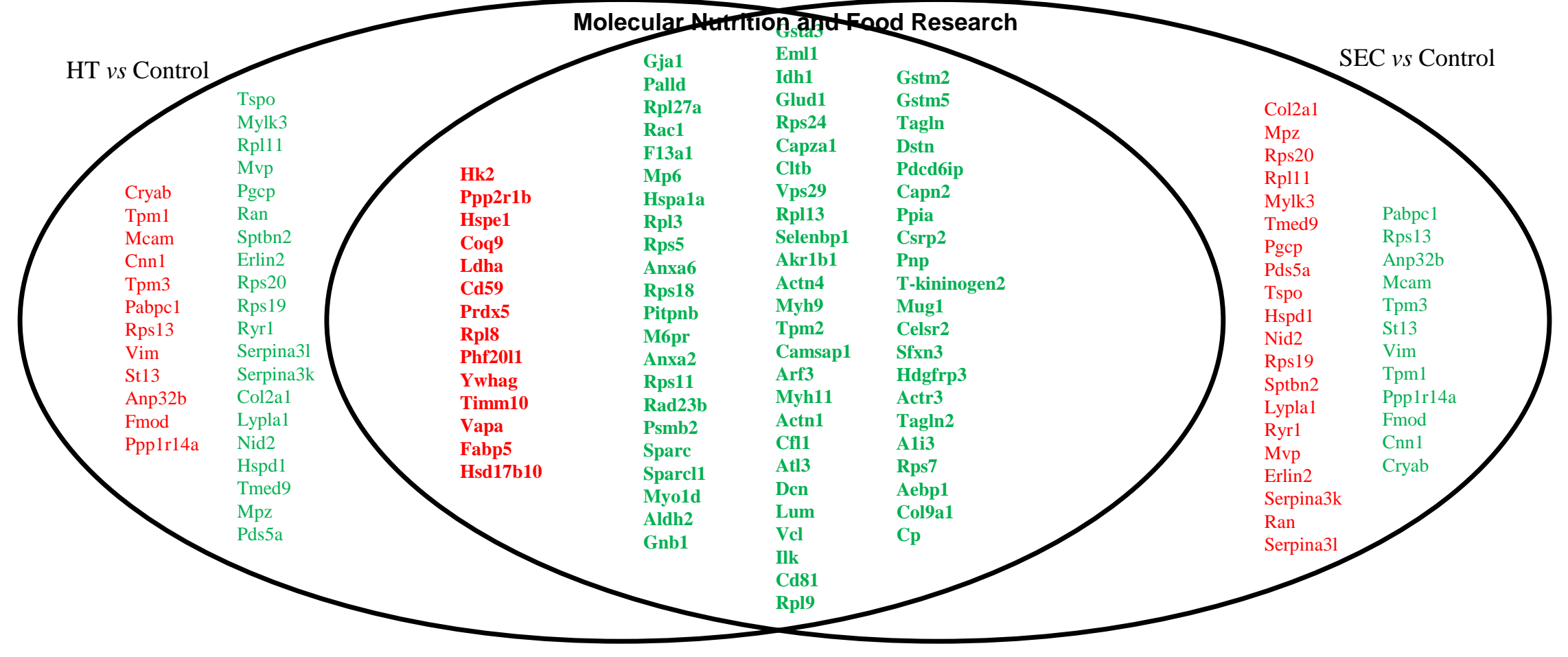

B

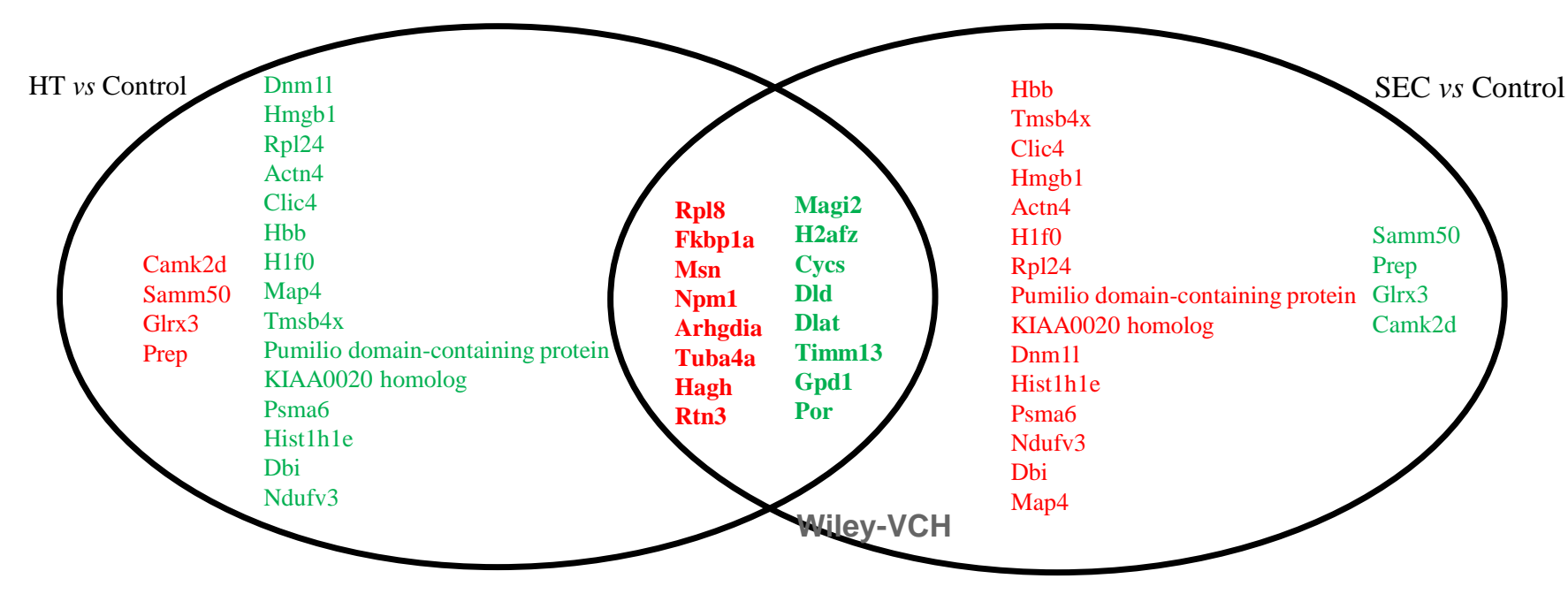



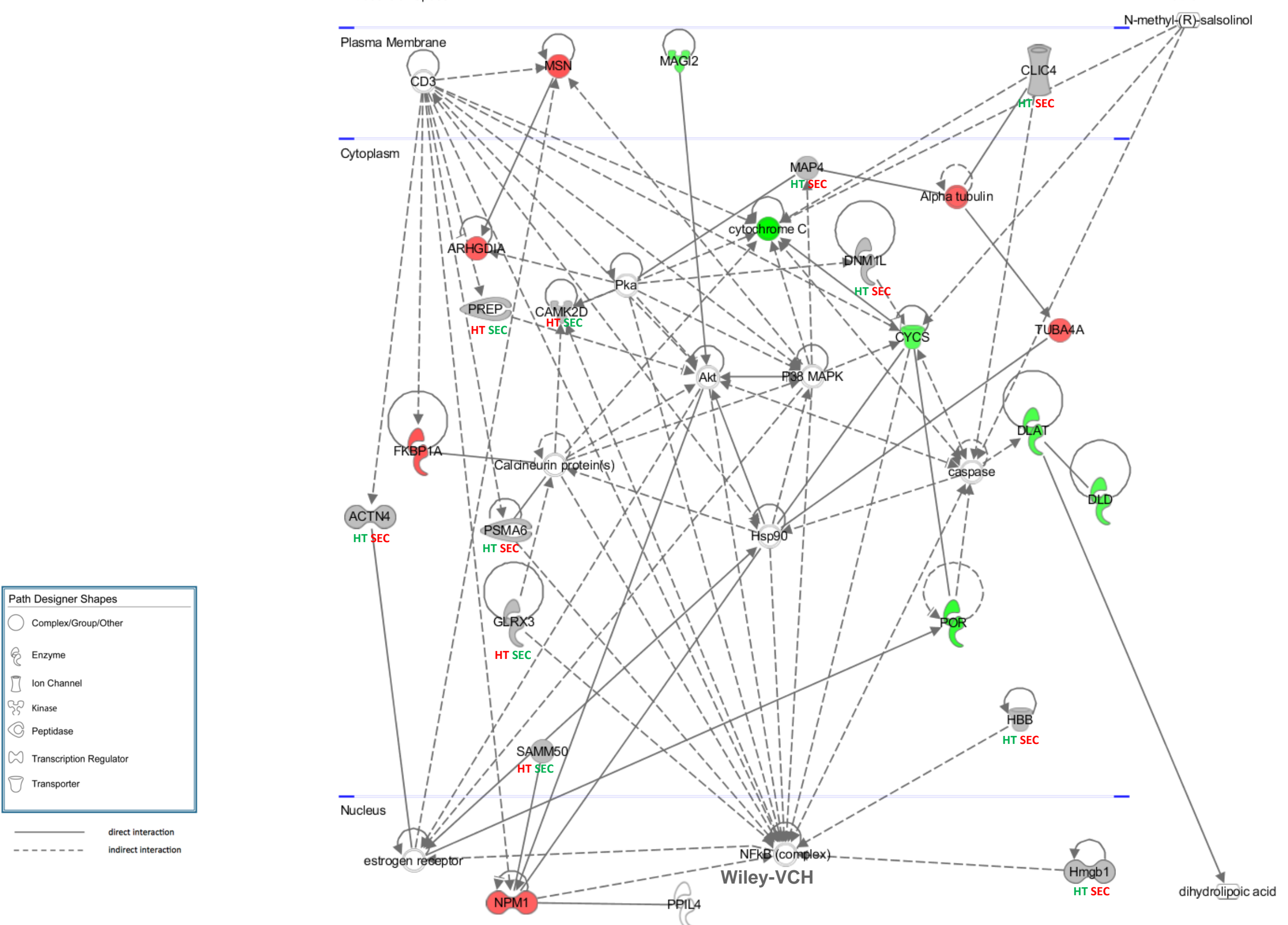